\title{
FBG Array Sensor Use for Distributed Internal Thermal Monitoring in Low Voltage Random Wound Coils
}

DOI:

10.1109/MECO.2017.7977124

Document Version

Accepted author manuscript

Link to publication record in Manchester Research Explorer

\section{Citation for published version (APA):}

Mohammed, A., \& Durovic, S. (2017). FBG Array Sensor Use for Distributed Internal Thermal Monitoring in Low Voltage Random Wound Coils. In 6th Mediterranean Conference on Embedded Computing (pp. 1-4). IEEE. https://doi.org/10.1109/MECO.2017.7977124

\section{Published in:}

6th Mediterranean Conference on Embedded Computing

\section{Citing this paper}

Please note that where the full-text provided on Manchester Research Explorer is the Author Accepted Manuscript or Proof version this may differ from the final Published version. If citing, it is advised that you check and use the publisher's definitive version.

\section{General rights}

Copyright and moral rights for the publications made accessible in the Research Explorer are retained by the authors and/or other copyright owners and it is a condition of accessing publications that users recognise and abide by the legal requirements associated with these rights.

\section{Takedown policy}

If you believe that this document breaches copyright please refer to the University of Manchester's Takedown Procedures [http://man.ac.uk/04Y6Bo] or contact uml.scholarlycommunications@manchester.ac.uk providing relevant details, so we can investigate your claim.

\section{OPEN ACCESS}




\section{FBG Array Sensor Use for Distributed Internal Thermal Monitoring in Low Voltage Random Wound Coils}

\author{
Anees Mohammed \\ Power and Energy Division \\ School of Electrical and Electronic Engineering \\ The University of Manchester \\ Manchester, UK \\ Anees.Mohammed@postgrad.manchester.ac.uk
}

\author{
Siniša Djurović \\ Power and Energy Division \\ School of Electrical and Electronic Engineering \\ The University of Manchester \\ Manchester, UK \\ Sinisa.Durovic@manchester.ac.uk
}

\begin{abstract}
This study examines the performance potential of FBG array thermal sensors for distributed monitoring of internal temperature in random wound electric coils. The sensor packaging and installation procedures are reported and its thermal monitoring performance assessed in laboratory tests on a prototype coil test system. The reported results indicate that a coil embedded FBG array thermal sensor can provide enhanced internal temperature monitoring and deliver information on thermal stress distribution within the coil structure.
\end{abstract}

Keywords-Fibre Bragg grating array sensors; distributed thermal monitoring; electrical windings; winding temperature; embedded sensing.

\section{INTRODUCTION}

Random wound coils are an essential component of most electric apparatus in modern industrial systems and have found widespread use in low voltage electric machinery. The effective use of electrical devices utilising random wound coils is limited by random wound coil design's sensitivity to electrothermal stresses experienced during operation. The coil thermal overloads are of particular concern in this respect as they can result in insulation breakdown and catastrophic failure [1]. This can be caused by excessive current levels in coil conductors but also by other reasons such as a failure in the integrated cooling system or a coil electrical fault, where localised hot spots are induced in the coil structure leading to insulation breakdown. The prospect of effective on-line distributed thermal monitoring of the coil structure is therefore attractive as it could enable improved understanding of the coil operational status and recognition of early stages of its degradation process, enabling remedial action to be undertaken before a catastrophic fault occurs [2].

Conventional techniques for thermal condition monitoring of random wound coils typically employ resistance temperature detector (RTD) or thermocouple (TC) thermal sensing technology. These sensors are however essentially suboptimal for embedded sensing solutions in current carrying coils due their size, EMI sensitivity and the presence of electrically conductive material in their structure. In addition the RTD and TC thermal sensors are not a preferable choice for distributed thermal sensing applications due to the length and volume of their wiring leads [3]. Fibre optic based FBG sensors on the other hand provide the required features for electric machinery and coil embedded applications in particular: EMI immunity, small dimensions, long lifetime, multi-point sensing/capability of multiplexing and general robustness [4-6].

The use of FBG temperature sensors for hot spot thermal monitoring in random wound coils has just started to attract attention [7-9]. The reported literature largely focuses on examining the potential of single point thermal measurement within the coil structure utilising a single FBG probe. In this paper the design and application of an array FBG sensor for distributed hot spot thermal monitoring within random wound coils is reported. The FBG array sensor was embedded in and its operation examined on a prototype coil wound of class $\mathrm{H}$ insulated copper wire, as is typical of most conventional random wound coils [10]. The paper reports the results of experimental tests in which the sensing array embedded test coil has been exposed to a range of static and dynamic thermal conditions. The purpose of this study is to examine the operational features of the array sensor use for distributed thermal monitoring and assess its practical performance potential in a typical low voltage test coil.

\section{FBG THERMAL SENSING PRINCIPLES}

FBGs are the periodic imprints made longitudinally on the optical fibre core to cause its refractive index to manifest a periodic modulation when exposed to an interference pattern of the ultraviolet laser light [11]. The wavelengths reflected by the FBG structure will change with the variation in the temperature and strain it is exposed to, thus enabling the grated fibre to be utilised as a thermal or a mechanical sensor with appropriate design. The FBG centre wavelength can be defined by [12]:

$$
\lambda_{\mathrm{B}}=2 \Lambda n_{\text {eff }},
$$

where: $\lambda_{\mathrm{B}}$ is the Bragg wavelength, $n_{\text {eff }}$ is the effective fibre core refractive index and $\Lambda$ is the grating period, i.e. the spacing between successive gratings. The reflected wavelength shift due to a temperature change can be expressed in terms of the fibre thermal characteristics as [11]:

$$
\Delta \lambda_{\mathrm{B}}=\lambda_{\mathrm{B}}(\alpha+\xi) \Delta T,
$$

where: $\alpha$ is the fibre thermal expansion coefficient and $\xi$ is the fibre thermo-optic coefficient [12]. FBG sensors can operate in temperatures up to $250{ }^{0} \mathrm{C}$ when imprinted in polyimide fiber with polyimide coating so are suitable for 
application in a vast majority of modern low voltage random wound coil applications [13].

FBG technology is particularly suitable for distributed sensing applications, where a single optical fibre can be used to contain a range of FBG sensing heads, with each head coded with a specific Bragg wavelength and acting as a separate sensor. This structure, known as an FBG array sensor, can provide attractive solutions for random wound coil embedded multi-point thermal sensing, where a single fibre optic probe could be applied to provide distributed sensing within the monitored coil structure. Fig .1 illustrates the operating concept of an FBG array sensor: the array is illuminated with broadband light and particular wavelengths reflected by each FBG sensing head. Each FBG reflects a specific light spectrum matching its designed Bragg wavelength. The process of fibre light excitation and examination of the reflected spectrum for Bragg wavelengths is managed by an interrogator device.

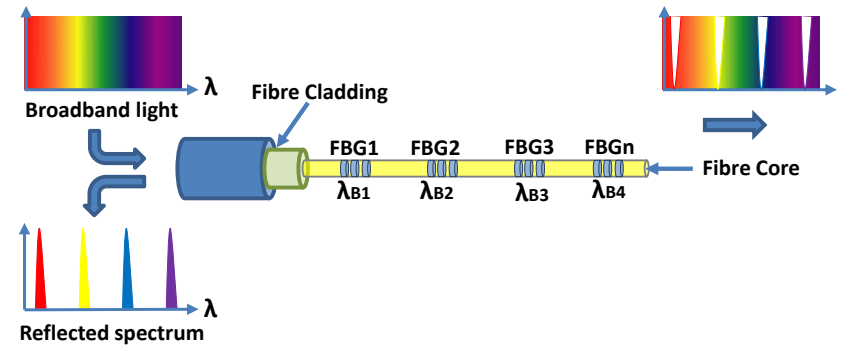

Figure 1. Operating principle of the FBG array sensor.

\section{TEST SYSTEM DESCRIPTION}

\section{A. FBG array sensor for in-situ monitoring}

Achieving distributed internal thermal monitoring of random wound coils using an FBG array sensor imposes a number of constraints on the appropriate sensor design. These largely arise from the electric current carrying wound coil environment that the sensor needs to safely operate in; the positioning of the sensor within the coil structure, placed amongst individual coil conductors, imposes the requirement of fibre optic sensor packaging to maintain its mechanical integrity. The bare array fibre and FBG heads are fragile and cannot be effectively utilised within the wound coil structure due to potentially destructive mechanical stress. For this purpose the array FBG sensor is packaged in a narrow nonconductive capillary; this provides mechanical protection for the sensing fibre and also ensures immunity to sensor excitation by mechanical effects so only thermal excitation is measured. The non-conductive capillary in this work is made from Polyetheretherketone (PEEK) which provides suitable dielectric, thermal and mechanical properties for this application [7]; this packaging material provides adequate mechanical strength for sensor isolation from strain/stress effects yet is sufficiently flexible to allow the sensor to be packaged into a coil shape required for installation into a wound coil structure. PEEK can withstand operating temperatures up to $250{ }^{0} \mathrm{C}$ which is ideally suited to the majority of modern low voltage random wound coil applications; it has a thermal conductivity of $0.173 \mathrm{w} / \mathrm{m} . \mathrm{K}$.

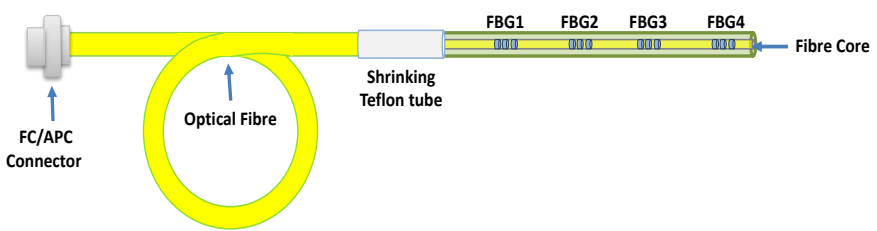

Figure 2. FBG array thermal sensor design for in-situ thermal monitoring.

Fig. 2 shows the schematic diagram of the packaged FBG array sensing probe used in this study. The array consists of four FBG heads imprinted in polyimide optic fibre with double polyimide coating. The FBG heads' length is $5 \mathrm{~mm}$ with Bragg wavelengths distributed in a bandwidth of 1529-60 $\mathrm{nm}$ and average reflectivity and bandwidth of $88 \%$ and 0.36 $\mathrm{nm}$, respectively. The total probe length is $1.5 \mathrm{~m}$ with the sensing region length of $\approx 30 \mathrm{~cm}$ defined by the length of the PEEK capillary containing the sensing heads. The capillary was chosen to have a diameter of $0.8 \mathrm{~mm}$ for compatibility with the conductor diameter in the examined wound coil design; the capillary wall thickness is $0.1 \mathrm{~mm}$. This sensor design allows the measurement of four internal temperature readings within the random wound coil with a single optic cable. In addition, the cross sectional area of the FBG array sensor has a negligible effect on the coil packing factor when compared to conventional TC or RTD thermal sensors.

\section{B. Experimental test design}

Experimental work was carried out on a prototype coil embedded with the designed FBG array temperature sensor. The prototype coil is wound on a winding machine to contain 40 turns of class $\mathrm{H}$ enamelled copper wire. The packaged array sensor was placed in the centre of the wound coil structure to be in near proximity of thermal hot spots of interest; this was achieved by first winding half the coil turns before placing the sensor package in its centre and winding the remainder of the coil turns. The resulting array sensor installation effectively takes the shape of a single turn centred in the wound coil's assembly. The array's four FBG heads were distributed within the coil structure so that two are placed in the coil sides (FBG2, FBG4) and the remaining two in the coil ends (FBG1, FBG3), as shown in the experiment setup illustrated in Fig. 3. The test coil was fixed to a support plate for the purpose of experimental work. A commercial SmartScan interrogator system was used to illuminate the sensor and enable dynamic measurement of reflected wavelengths. The interrogator was connected to a personal computer running LabVIEW code to record and analyse the measured data.

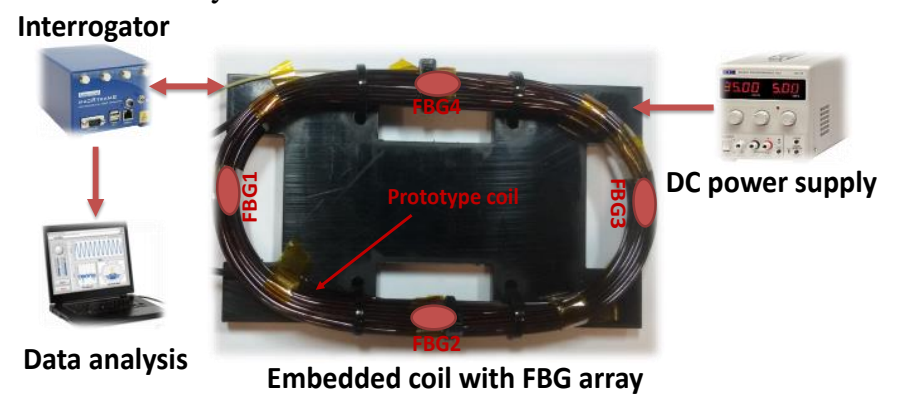

Figure 3. Experimental test setup. 
The test coil was exposed to steady-state and transient thermal stress in experiments using appropriate DC current excitation provided by a controlled DC power supply. This enabled examination of the sensing performance of the embedded FBG array sensing system. To enable the evaluation of sensing performance under uneven thermal stress distribution in the coil a separately excited DC coil wound around the structure of the test coil was used to provide localised thermal stress, as detailed in section IV.

\section{RESULTS AND DISCUSSION}

The interpretation of the measured reflected peak wavelengths from each FBG head in the array to temperature readings requires a calibration test, which yields a temperaturewavelength fit curve for each FBG head [7, 8]. The calibration test was carried out using a commercial thermal chamber.

The prototype coil embedded with an FBG array sensor was placed in the thermal chamber and exposed to a range of static thermal stress. The FBG array sensor was calibrated in the temperature range of $\approx 40$ to $\approx 170{ }^{\circ} \mathrm{C}$ in a rising sequence of $\approx 10{ }^{\circ} \mathrm{C}$ steps, to match the thermal rating of the examined class $\mathrm{H}$ insulated coil. Measurements were taken at every examined thermal steady-state once the thermal equilibrium was achieved. Fig. 4 shows the data recorded during the calibration test; the calculated parameters of the second order polynomial fit curves for each FBG head are listed in Table I. The table also includes the calculated standard error for each parameter and the calculated correction coefficient for each FBG head. The four FBG heads are seen to show good linearity with a correction factor coefficient higher than 0.999 .

The distributed thermal monitoring performance of the coil embedded FBG array sensor was evaluated in static and dynamic thermal tests. To enable the assessment of steady-state thermal monitoring performance, the embedded coil was first injected with a $3 \mathrm{~A}$ DC current giving $\approx 4.2 \mathrm{~W}$ power loss dissipated as heat. Fig. 5 shows the temperature measurement

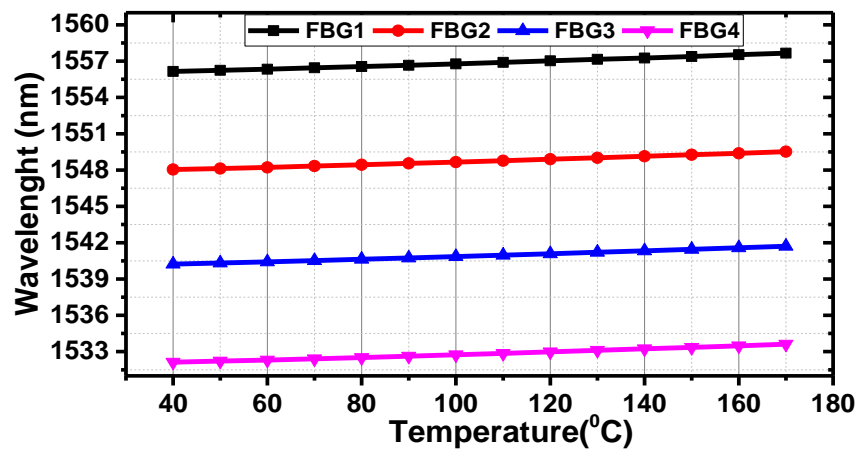

Figure 4. Calibration characteristics of the packaged FBG array sensor heads.

TABLE I

CALCULATED FIT CURVE PARAMETERS

\begin{tabular}{|c|c|c|c|c|c|c|c|}
\hline & \multicolumn{2}{|c}{ Intercept } & \multicolumn{2}{c|}{ B1 } & \multicolumn{2}{c|}{ B2 } & Statistics \\
\hline & Value & Standard Error & Value & Standard Error & Value & Standard Error & Adj. R-Square \\
\hline FBG1 & 1555.771 & 0.0137 & 0.00855 & $2.85 E-04$ & $1.50 E-05$ & $1.34 E-06$ & 0.99978 \\
\hline FBG2 & 1547.669 & 0.01122 & 0.00851 & $2.34 E-04$ & $1.41 E-05$ & $1.10 E-06$ & 0.99985 \\
\hline FBG3 & 1539.852 & 0.01012 & 0.00871 & $2.11 E-04$ & $1.30 E-05$ & $9.90 E-07$ & 0.99988 \\
\hline FBG4 & 1531.768 & 0.01308 & 0.00808 & $2.72 E-04$ & $1.67 E-05$ & $1.28 E-06$ & 0.9998 \\
\hline
\end{tabular}

obtained by the four FBGs from ambient temperature, including a detailed view of steady-state thermal measurements for clarity. Individual FBG measurements obtained in different coil locations are seen to exhibit close internal temperature readings that are within $\approx 1.5{ }^{0} \mathrm{C}$. While the power loss induced by the coil resistance is relatively small at $\approx 4.2 \mathrm{~W}$, it generates coil internal hotspot temperatures of $\approx 76{ }^{0} \mathrm{C}$. This is expected as the induced heat is dissipated from the coil to the surrounding ambient by convection, which is an inherently slow heat transfer process. The average internal coil temperature measured at steady-state is $\approx 75.5^{\circ} \mathrm{C}$.

The dynamic thermal monitoring performance of the FBG array sensing system was assessed in an intermittent periodic duty cycle, performed by appropriate modulation of the coil excitation current. A sequence of identical thermal cycles was applied by regular switching of the DC current level from zero to constant $6 \mathrm{~A}$. The total applied periodic thermal cycle duration is 10 mins, including a 4 min period of increasing thermal stress (i.e. constant 6A current flow) followed by a 6 min cooling period (i.e. zero current flow). This provides a representative dynamic thermal profile that is within the thermal rating of the examined coil design. The data measured in the dynamic test are shown in Fig. 6. The applied periodic duty cycle is reported by the embedded sensor to induce an internal temperature cycle in the range of $\approx 44$ to $\approx 138{ }^{0} \mathrm{C}$ within the tested coil. The transient thermal profiles recorded by individual FBGs are seen to be in close agreement and show good repeatability. The obtained results clearly demonstrate the capability of effective multi-point internal thermal sensing for on-line thermal monitoring using the proposed FBG array sensor.

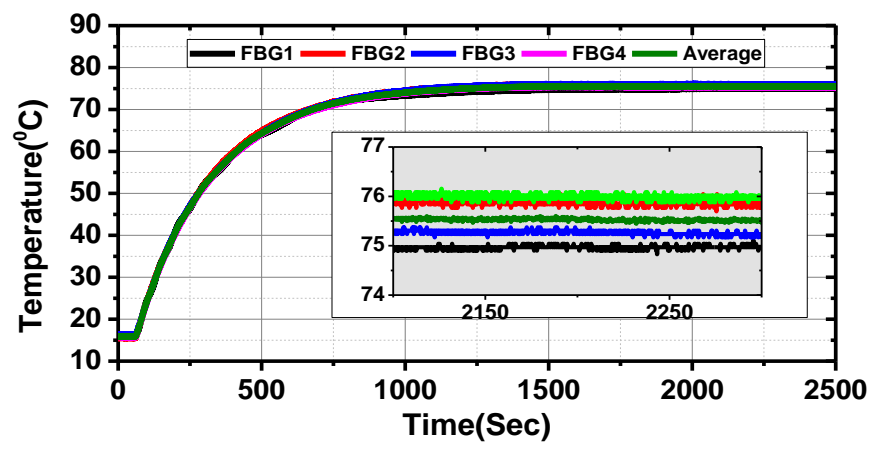

Figure.5. FBG array thermal measurements in steady state condition.

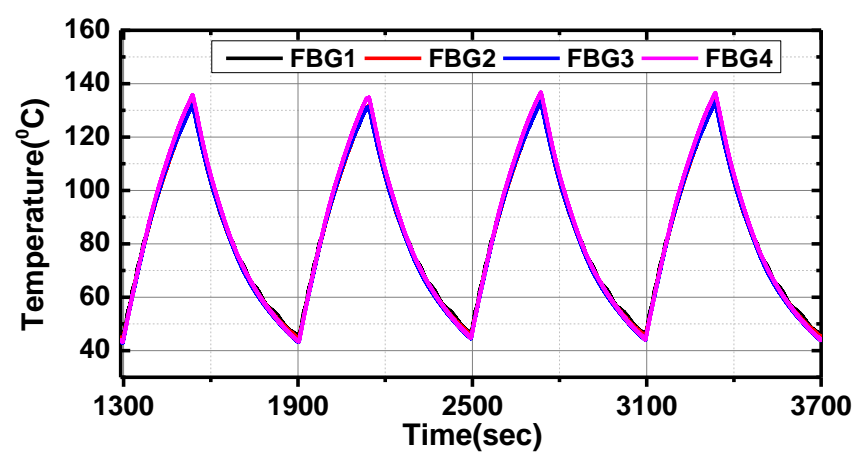

Figure.6. FBG array thermal measurements in transient condition. 
A particularly attractive feature of distributed thermal monitoring is the capability of identification of excessive localised thermal stress within the coil structure which in practical applications can often be an early sign of a possible degradation process. Acquiring a single localised thermal reading of the entire coil's internal temperature will not be adequate for providing full information about the coil thermal state in such condition, as the position of the excessive thermal stress induced hot spot is difficult to predict and could be anywhere within the coil structure. Distributed internal thermal sensing can, in principle, provide an adequate solution as it delivers multi-point thermal measurement in different locations within the coil structure.

To examine the embedded distributed thermal monitoring performance in a localised high thermal stress operating scenario an additional, external, 20 turn coil was wound around a section of the test coil where FBG4 sensing head is positioned, as illustrated in Fig. 7. The external coil was energised with a constant DC current of $10 \mathrm{~A}$ in the tests to provide localised increased thermal stress in the main test coil embedded with the FBG array sensor. The main coil was first excited with a DC current of $3 \mathrm{~A}$ in the tests and once the thermal steady-state was reached the external coil was energised to provide additional localised stress. This procedure results in unequal thermal conditions within the main coil structure as the external coil induced heat will be unevenly dissipated in the tested coil.

Fig. 8 shows the array sensor thermal measurements obtained in the performed test. The first $75 \mathrm{sec}$ in the plot represent the temperature readings before the external coil is excited. The four FBGs exhibit a closely similar transient profile in this period. Once the external coil is excited there is an obvious change in the distributed readings, where FBG4 records the highest temperature $\left(\approx 128.6{ }^{\circ} \mathrm{C}\right)$ and FBG2 the lowest $\left(\approx 117.6{ }^{0} \mathrm{C}\right)$, while FBG1 and FBG3 report very similar readings $\left(\approx 122.7\right.$ and $\left.\approx 121.6{ }^{0} \mathrm{C}\right)$. The recorded differences between FBG head readings correspond to their distribution in the test coil structure. A difference of $\approx 10{ }^{0} \mathrm{C}$ between the point of highest and lowest thermal stress in the coil was reported by the embedded array sensor, illustrating the advantages in recognition of localised hot spots of high thermal stress by using distributed thermal sensing based on FBG technology.

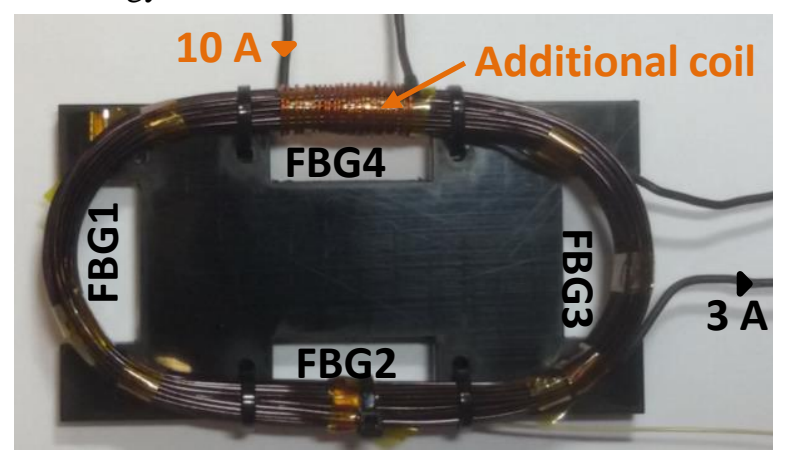

Figure.7. Illustration of external coil use for localised high thermal stress.

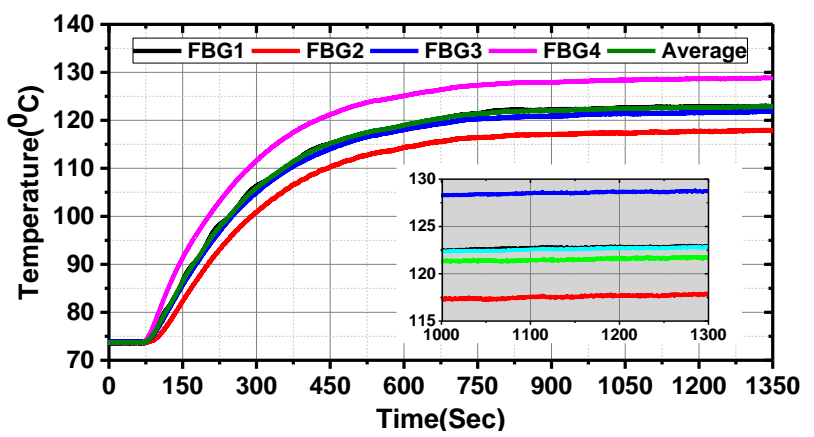

Figure.8. Thermal measurements under non-uniform thermal stress.

\section{CONCLUSIONS}

This work reports a performance assessment of a dielectric packaged FBG array for internal distributed thermal sensing in low voltage random wound coils. The study undertakes a number of experiments on a prototype FBG array enabled random wound coil under controlled steady-state and transient thermal conditions. It is shown that the utilisation of a packaged array sensor has significant potential to facilitate effective recognition of multiple localised points of thermal stress in the wound coil structure.

\section{References}

[1] G. C. Stone, E. A. Boulter, I. Culbert and H. Dhirani, "Electrical insulation for rotating machines-design, evaluation, aging, testing, and repair," in IEEE El. Ins. Mag., vol. 20, no. 3, pp. 65, June 2004.

[2] H. Zhang, "Online Thermal Monitoring Models for Induction Machines," in IEEE Trans. on En. Conv., vol. 30, no. 4, pp. 1279-1287, Dec. 2015.

[3] "IEEE Recommended Practice for General Principles of Temperature Measurement as Applied to Electrical Apparatus," in IEEE Std 119-1974.

[4] C. Martelli et al., "Temperature sensing in a $175 \mathrm{MW}$ power generator," Proc. SPIE 8421, OFS2012 22nd Int. Conf. on Optical Fiber Sensors.

[5] D. S. Vilchis-Rodriguez, S. Djurović, P. Kung, M. I. Comanici and A. C. Smith, "Investigation of induction generator wide band vibration monitoring using fibre Bragg grating accelerometers," 2014 International Conference on Electrical Machines (ICEM), Berlin, 2014, pp. 1772-1778.

[6] D.S. Vilchis-Rodriguez, S. Djurovic , P. Kung , M. I. Comanici ; S. Scepanovic; K. Tshiloz; A. C. Smith, "Wide band fiber Bragg grating accelerometer for rotating AC machinery condition monitoring," Proc. SPIE Vol. 9288, Photonics North 2014, pp.1-10, September 25, 2014.

[7] A. Mohammad, S. Djurović, "Evaluation of fiber-optic sensing performance for embedded thermal monitoring of electric machinery wound components," 2016 5th Mediterranean Conference on Embedded Computing (MECO), Bar, 2016, pp. 72-76.

[8] A. Mohammed, S. Djurović, A. C. Smith and K. Tshiloz, "FBG sensing for hot spot thermal monitoring in electric machinery random wound components," 2016 XXII International Conference on Electrical Machines (ICEM), Lausanne, Switzerland, 2016, pp. 2266-2272.

[9] K. Tshiloz, A. C. Smith, A. Mohammed, S. Djurović and T. Feehally, "Real-time insulation lifetime monitoring for motor windings," 2016 XXII International Conference on Electrical Machines (ICEM), Lausanne, 2016, pp. 2335-2340.

[10]A. Siddique, GS. Yadava, and B. Singh, "A review of stator fault monitoring techniques of induction motors," Energy conversion, IEEE transactions on 20.1 (2005): 106-114.

[11] Rao, Yun-Jiang, "In-fibre Bragg grating sensors," Measurement science and technology 8.4 (1997): 355.

[12]A. D. Kersey, M. A. Davis, H. J. Patrick, M. LeBlanc, K. P. Koo, C. G. Askins, M. A. Putnam, and E. J. Friebele, "Fiber grating sensors." Journal of lightwave technology 15, no. 8 (1997): 1442-1463.

[13]https://www.smartfibres.com/products/smartfbg 